\title{
Special Genetic Stocks against Paddy Blast (Pyricularia oryzae)
}

\author{
Prafull Kumar $^{1 *}$, Kiran Tigga ${ }^{2}$, Abhinav $\mathrm{Sao}^{3}$ and R.S. Netam ${ }^{1}$ \\ ${ }^{1}$ SGCARS, Jagdalpur, IGKV, Raipur, Chhattisgarh, India \\ ${ }^{2}$ RMDCARS Ambikapur, IGKV, Raipur, Chhattisgarh, India \\ ${ }^{3}$ Department of GPB, COA, Raipur, Chhattisgarh, India \\ *Corresponding author
}

\section{A B S T R A C T}

The trireplicated field experiment was conducted at Rice Research Block of S. G. College of Agriculture and Research Station, Jagdalpur, Chhattisgarh, India with 6 test entries, 2 recurrent parents and 2 donor parents. BPT 5204 (Samba Mahsuri) the recurrent parent 1 (RP 1) for the four test genotype recorded average plot yield of $4.00 \mathrm{~kg} / \mathrm{ha}$ placing second

\section{Keywords}

NILs, Recurrent parent, Doner Parent, Blast

\section{Article Info}

Accepted:

10 March 2018

Available Online: 10 April 2018 in the experiment. None of the entry recorded on par with recurrent parent 01 statically however, all the genotypes no significant difference was observed with respect to grain yield. When the recurrent parent 02 (Improved Sambha Mahsuri) was taken into account, genotype RP-Patho-1-2-15 recorded higher plot yield $(4.23 \mathrm{~kg})$ and was at par. Flowering duration wise, RP-Patho-1-2-15 and RP-Patho-3-56-11 were similar to the recurrent parent with flowering of 78 and 79 DAS accordingly while RP-Patho-3-73-6 was six days in advance (70 days) to the recurrent parent (76 days). All the test isogenic lines with a plant height of $79-85 \mathrm{~cm}$ were similar to the recurrent parent $(82 \mathrm{~cm})$. Blast and bacterial leaf blight resistance gene carrying genotypes RP-Patho-2-18-5 and RP-Patho-2-16-4 gave plot grain yield $3.77 \mathrm{~kg}$, which out yielded recurrent parent 02 but lesser than recurrent parent 01. However flowering was delayed (96 DAS and 99 DAS) and plant height was increased in both the isogenic lines $(83 \mathrm{cms}$ and $81 \mathrm{cms})$. Summarily, all the genotypes were similar to recurrent parent, indicating the recovery of crossed material to desired genetic background.

\section{Introduction}

Rice production is constrained by substantial number of fungal, bacterial and viral origin diseases. Rice blast (caused by Magnaporthe grisea) and bacterial leaf blight (BLB, caused by Xanthomonas oryzae pv. Oryzae, Xoo) are two most destructive diseases leading to severe yield losses in rice production worldwide (Zhan et al., 2012). Rice blast, caused by the filamentous ascomycete fungus
Magnaporthe oryzae (anamorph Pyricularia oryzae), is major threats for rice production and leads to significant yield loss, as high as 70-80\% during an epidemic (Khush, 2009). Host plant resistance is emerging as most effective, economical and environmentally safe measure for controlling paddy blast in combination with pathological management. So far, 73 blast resistance genes have been identified (Sujatha et al., 2011) and some of them have been incorporated into modern rice 
varieties (Sundaram et al., 2008; 2009) through marker assisted selection (MAS). Among these, few genes like $P i-1, P i-2, P i-9$, $P i-54$ etc. (for blast resistance) are being extensively used in rice breeding programmes globally as are highly effective and having tightly linked molecular markers. With these background, some of the ICAR-IIRR (Formerly DRR) Hyderabad developed MAS breeding lines, obtained under AICRIP programme, possessing high level of resistance against blast (conferred by Pil or Pi54) and bacterial blight (conferred by Xa21) was evaluated for blast resistance in Bastar plateau of Chhattisgarh.

\section{Materials and Methods}

The test genotypes were obtained from Indian Institute of Rice Research, (ICAR-IIRR, formerly DRR), Hyderabad under AICRIP programme. The trial was constituted with 6 test entries, 2 recurrent parents and 2 donor parents.

The trireplicated field experiment was conducted at Rice Research Block of S. G. College of Agriculture and Research Station, Jagdalpur, Chhattisgarh, India in Kharif 201314 with $5 \times 3 \mathrm{~m}$ (gross plot) plot size, Randomized Complete Block Design. Standard agronomic package was followed to raise the crop.

Restriction selection indice was constructed based on previous research review and four quantitative parameters were selected for genetic evaluation.

The observation was recorded on net plot basis (heading date and plot yield), unit plot basis (panicles/sq M) and arithmetic mean basis among random selections. Days to 50 percent flowering was recorded when half of plant flowered among the plot. Panicle count was made with one square meter square at maturity. The disease scoring was made visually giving the score 1-9. Statistical analysis was done with SPARK 2.

\section{Results and Discussion}

The experimental yield ranged from $2.67 \mathrm{~kg} /$ plot (Improved sambha Mahsuri) to 4.23/plot (RP-Patho-1-2-15). The Recurrent parent 01 (BPT 5204) was the earliest to flower with $50 \%$ flowering in 91 DAS followed by donor parent 01 (92 DAS) while RP-Patho-1-2-15 and RP-Patho-3-73-6 recorded to be late flowering genotypes with 113 DAS days to 50 percent flowering. The experimental mean for blooming period was 101 DAS. RP-Patho-3-73-6, BPT 5204 and RP-Patho-1-2-15 were short in plant height (70, 76 and $78 \mathrm{cms}$ respectively) while Tetep was recorded to be tallest (115 cms) (Table 1) whereas, the mean plant height was reported to be 84.5 cms. Panicles count was significantly higher for BPT 5204, RP-Patho3-73-11 and RP-Patho-1-6-5 (348, 324 and 312 correspondingly) while RP-Patho-1-2-15 and Tetep exhibited comparative lower count. The grain yield was in perfect direction with panicles number. BPT 5204 (Samba Mahsuri) the recurrent parent 1 (RP 1) for the four test genotype recorded average plot yield of 4.00 $\mathrm{kg} / \mathrm{ha}$ placing second in the experiment. None of the entry recorded on par with recurrent parent 01 statically however, all the genotypes no significant difference was observed with respect to grain yield. When the recurrent parent 02 (Improved Sambha Mahsuri) was taken into account, genotype RP-Patho-1-2-15 recorded higher plot yield $(4.23 \mathrm{~kg})$ and was at par. Flowering duration wise, RP-Patho-1-215 and RP-Patho-3-56-11 were similar to the recurrent parent with flowering of 78 and 79 DAS accordingly while RP-Patho-3-73-6 was six days in advance (70 days) to the recurrent parent (76 days). All the test isogenic lines with a plant height of $79-85 \mathrm{~cm}$ were similar to the recurrent parent $(82 \mathrm{~cm})$. 
Int.J.Curr.Microbiol.App.Sci (2018) 7(4): 1217-1221

Table.1 Ancillary traits data following restriction selection indices

\begin{tabular}{|c|c|c|c|c|c|c|c|c|}
\hline & \multicolumn{2}{|c|}{ Plant height (cm) } & \multicolumn{2}{|c|}{ Days to $\mathbf{5 0}$ percent flowering } & \multicolumn{2}{|c|}{ Panicles/sqm } & \multicolumn{2}{|c|}{ Grain yield/Plot } \\
\hline & Mean & SE & Mean & $\mathrm{SE}( \pm)$ & Mean & $\mathrm{SE}( \pm)$ & Mean & $\mathrm{SE}( \pm)$ \\
\hline RP- Patho-1-2-15 & 78 & 4.98 & 113 & 0.88 & 257 & 12.42 & 4.23 & 0.15 \\
\hline RP- Patho-1-6-5 & 90 & 3.84 & 108 & 0.33 & 312 & 24.12 & 3.87 & 0.41 \\
\hline RP- Patho-3-56-11 & 79 & 4.33 & 113 & 0.83 & 324 & 12.2 & 3.7 & 0.3 \\
\hline RP- Patho-3-73-6 & 70 & 4.97 & 107 & 1.16 & 331 & 12.44 & 3.03 & 0.35 \\
\hline RP- Patho-2-18-5 & 83 & 4.33 & 99 & 0.88 & 286 & 7.26 & 3.87 & 0.26 \\
\hline RP- Patho-2-16-4 & 81 & 3.18 & 96 & 0.81 & 272 & 5.81 & 3.87 & 0.23 \\
\hline BPT 5204 (RP 1) & 76 & 4.63 & 91 & 0.67 & 348 & 10.1 & 4 & 0.17 \\
\hline Improved Samba Mahsuri (RP 2) & 82 & 2.72 & 94 & 0.58 & 276 & 8.95 & 2.67 & 0.09 \\
\hline Tetep (DP 1) & 115 & 4.53 & 92 & 0.57 & 264 & 6.96 & 3.17 & 0.34 \\
\hline C 101 LAC (DP 2) & 91 & 3.53 & 98 & 0.33 & 300 & 10.44 & 3.43 & 0.2 \\
\hline
\end{tabular}


Blast and bacterial leaf blight resistance gene carrying genotypes RP-Patho-2-18-5 and RPPatho-2-16-4 gave plot grain yield $3.77 \mathrm{~kg}$, which out yielded recurrent parent 02 but lesser than recurrent parent 01. However flowering was delayed (96 DAS and 99 DAS) and plant height was increased in both the isogenic lines $(83 \mathrm{cms}$ and $81 \mathrm{cms})$. The same trend was continued with panicle count. The donor lines Tetep (DP 1) and C 101 LAC (DP 2) showed optimal adaption to Southern Chhattisgarh rice growing ecology. Average plant height of Tetep was $91 \mathrm{cms}$ and attained 50 percent flowering by 98 DAS. Since vegetative span was lengthened, panicle count (300) and plot yield also increased accordingly (3.43). Taking into account another donor parent (Tetep), it exhibited faster growth rate and attained $115 \mathrm{cms}$ plant height by 92 DAS of preflowering period. Compare to DP 2 produced lesser panicle population (264) and plot grain yield $(3.15 \mathrm{~kg})$ (ICAR-DRR, 2014).

Visual observation showed that all the near isogenic lines were parallel to the respective recurrent parent; blast prevalence was modest in both Recurrent Parents. Incidence of blast reported in Tetep (1-2\%), C 101 LAC (8$10 \%)$, all isogenic lines (5-8\%). Blast resistance genes $\mathrm{Pi} 1$ carrying genotypes RPPatho-1-2-15 and RP-Patho-1-6-5, the infestation the comparatively higher (Score 6) however those with Pi 54 (RP-Patho-3-56-11 and RP-Patho-3-73-6). Similarly RP-Patho-356-11 and RP-Patho-3-73-6, having the blast resistance gene, ( $\mathrm{Pi}$ 54) showed average disease incidence (Score 4). However, dual genetic resistance background i.e. both blast and bacterial blight resistance genes $X a 21+$ $\mathrm{Pi}$-54; provided excellent resistance even in hot spot centre for the disease. In previous studies multiple resistance gene pyramiding has been reported by Chen et al., 2009 and Zhan et al., (2012). In genotype RP-Patho-216-4 the disease was scaled to be 01 , which was quite similar to recurrent parent 02 (Improved Sambha Mahsuri). Visual evaluation of donor parents revealed average disease incidence (score 4). Reproductive behaviour was similar to BPT 5205 and Improved Sambha Mahsuri for all genotypes except RP-Patho-1-2-15 and RP-Patho-2-16-4 but it may attribute to $\mathrm{G} \times \mathrm{E}$ interactions rather than genetic segregation. Similarly, for above ground plant canopy length all test genotypes were relatively more closure to both the recurrent parents which shows comparative expression of photosynthates source sink balance in Near Isogenic Lines (NILs). However, donor parent i.e. Tetep; plant height was significantly higher might be due to regional quantitative adaptability (Kumar et al., 2015). Looking for sink strength, BPT 5205 recorded significantly higher potential of dry matter accumulation than remaining population due to genetic establishment in given environment. Parallel observation was recorded for RP-Patho-3-5611, RP-Patho-3-73-6 and RP-Patho-2-18-5 showing potent leaf blast and bacterial leaf blight resistance for Southern province of Chhattisgarh. Ultimately, when crop yield was taken into account, the normal distribution curve shifted towards the recurrent parent 01 and the entire test entries lied between $1750 \mathrm{~kg} / \mathrm{ha}$ to $3075 \mathrm{~kg} / \mathrm{ha}$. Summarily, sustainable yield potential was realized despite of target disease incidence all genotypes may be considered as resistance genotypes.

With advances in molecular biology, breeding for resistance genes has become wise and efficient strategy in crop improvement. In present investigation evaluation was made of DRR bred materials for hot spot of paddy blast. All the genotypes were similar to recurrent parent with respect to flowering duration, canopy length, and plot grain yield and disease reaction indicating the recovery of crossed material to desired genetic 
background after introgression of dual resistance gene and equally and effectively even in hot spot centre for the disease.

\section{Acknowledgement}

The authors acknowledge Indian Institute of Rice Research (ICAR-IIRR formerly DRR), Hyderabad for providing study material and financial support.

\section{References}

Chen, H. Q., Chen, Z. X., Ni, S., Zuo, S. M., Pan, X. B., Zhu, X. D. 2008. Pyramiding three genes with resistance to blast by marker-assisted selection to improve rice blast resistance of Jin23B. Chin J Rice Sci., 22: 23-27. (in Chinese with English abstract)

Chen, J. M., Fu, Z. Y., Quan, B. Q., Tian, D. G., Li, G., Wang, F. 2009. Breeding hybrid rice restoring line with double resistance to rice blast and bacterial blight by marker-assisted selection. Mol Plant Breeding, 7(3): 465-470.

Directorate of Rice Research. 2014. Progress Report, 2013. Vol.1, Varietal Improvement. All India Coordinated Rice Improvement Programme (ICAR). Directorate of Rice Research, Rajendranager, Hyderabad-500030, India.

Khush, G. S. and Jena, K. K. 2009. Current status and future prospects for research on blast resistance in rice (Oryza sativa L.). In: G. L. Wang, and B. Valent (eds), Advances in Genetics, Genomics and Control of Rice Blast Disease, 1-10. Springer, New York.

Kumar, Prafull, Sao, A., Kanwar. R.R. and Salam, J.L. 2015. AMMI Biplot analysis and Genotype x Environment interaction studies in rainfed upland rice accessions. Oryza, 52 (1): 27-33.

Sujatha, K., Natarajkumar, P., Laha, G.S., Mishra, B., Srinivasa Rao, K., Viraktamath, B.C., Kirti, P.B., Hari, Y., Balachandran, S.M., Rajendrakumar, P., Ram, T., Hajira, S.K., Madhav, M.S., Neeraja, C.N., and Sundaram, R.M. 2011. Inheritance of bacterial blight resistance in the rice cultivar Ajaya and high-resolution mapping of a major QTL associated with resistance. Genet. Res. Camb., 93: 397-408.

Sundaram, R. M., Vishnupriya, M. R., Laha, G. S., Shobha Rani, N., Srinivas Rao, P., Balachandaran, S. M., Reddy, G. A., Sarma, N. P. and Shonti R. V. 2009. Introduction of bacterial blight resistance into Triguna, a high yielding, mid-early duration rice variety. Biotechnol. J., 4:400-407.

Sundaram, R.M., Vishnupriya, M.R., Birdar, S.K., Laha, G.S., Reddy G.A., Shoba Rani, N., Sarma, N.P., and Ramesh, V. S. 2008. Marker assisted introgression of bacterial blight resistance in Samba Mahsuri, an elite indica rice variety. Euphytica, 160: 411-422.

Zhan, X.D., Zhou, H.P., Chai, R.Y., Zhuang, J.Y., Cheng, S.H. and Cao, L.Y. 2012. Breeding of $\mathrm{R} 8012$, a rice restorer line resistant to blast and bacterial blight through marker-assisted selection. Rice Science, 19(1): 29-35.

\section{How to cite this article:}

Prafull Kumar, Kiran Tigga, Abhinav Sao and Netam, R.S. 2018. Special Genetic Stocks against Paddy Blast (Pyricularia oryzae). Int.J.Curr.Microbiol.App.Sci. 7(04): 1217-1221. doi: https://doi.org/10.20546/ijcmas.2018.704.135 